\title{
Research on high precison DEM of urban area based on TerraSAR-X/TanDEM-X
}

\author{
Ertao Gao ${ }^{1,2, *}$, Yanping $\operatorname{Lan}^{1}$, Yi Luo ${ }^{1}$, Shuaiyin $\mathrm{Ge}^{1}$, Hangming $\mathrm{Yu}^{1}$, Pengde $\mathrm{Lai}^{1}$ \\ ${ }^{1}$ College of Geomatics and Geoinformation; Guilin University of Technology, Guilin, China - gaoertaoswjtu@163.com \\ ${ }^{2}$ Guangxi Key Laboratory of Spatial Information and Geomatics, Guilin University of Technology, Guilin, China
}

KEY WORDS: InSAR; DEM; TerraSAR-X/TanDEM-X; Maanshan; fusion

\begin{abstract}
:
Digital elevation model (DEM) is an important geospatial data, which can provide a lot of topographic information. Currently, most commonly DEM data is derived from SAR images acquired before 2011, which has poor timeliness and is difficult to reflect the latest topographic features in many areas, especially in urban areas where the topographic features are rapidly updated. Therefore, it is necessary to explore DEM generation methods in urban areas to provide technical support for further studies on municipal planning and surface deformation in urban areas.

This paper used two SAR images with bistatic mode, single-polarization (HH), and single look complex as experimental data from TerraSAR-X/TanDEM-X. The imaging time was January 30, 2013. The spatial baseline was $248.467 \mathrm{~m}$. The research obtained good timeliness and high-resolution DEM of Maanshan area based on the iteration and fusion technology using two TerraSAR$\mathrm{X} /$ Tandem-X SAR images and AW3D30 DEM from JAXA/EORC.

With a comparison of $90 \mathrm{~m}$ SRTM and $30 \mathrm{~m}$ AW3D30, this paper found that the DEM based on iteration and fusion technology could show more ground details, especially for the large single buildings at the sparse area. However, the extracted DEM at the dense-buildings area had the low reliability and still needed to further explore the solution, due to the obstruct of sensor line of sight and the distribution of shadow.

In conclusion, this paper confirmed that it is feasible to obtain high-resolution and high time efficiency DEM using the iteration and fusion technology. It is able to improve the resolution of DEM and update the topographic from the original DEM by iteratively fused with AW3D30 to eliminate overlay and shadow.
\end{abstract}

\section{INTRODUCTION}

With the acceleration of urbanization in the current era, the changes in topographic and geomorphic information on urban areas are also accelerating. Digital elevation model data is an important geospatial data, which provides strong data support for urban structure analysis and rapid acquisition of urban realtime information, and widely applied to various fields (Campbell et al., 2013; James et al., 2012; Nikolakopoulos et al., 2006). At present, the global digital elevation models commonly used in the world are: SRTM obtained by the National Aeronautics and Space Administration (NASA) in 2000 (Rabus et al., 2003; Rawat et al., 2013); NASA and the Ministry of Economy, Trade and Industry (METI) ) ASETR GDEM (Rawat et al., 2013; Gesch et al., 2012) co-published in 2009 and 2011; AW3D30 (ALOS World 3D-30m) released by the Japan aerospace agency earth observation research center (JAXA/EORC) in 2016 (Jain et al., 2017). The accuracy of these DEMs has been greatly improved, but they are all acquired based on image from before 2011, so the timeliness was poor.

Interferometry Synthetic Aperture Radar (InSAR) is a microwave remote sensing technology rising in the 1980s. Its main advantage is that it can penetrate the clouds, vegetation and the surface to measure in all-weather and all time without restriction of weather. And with a wide coverage area and high spatial resolution, consequently, it is a potential space-to-earth observation technology (Bürgmann et al., 2000; Zhu et al., 2017; Zeng et al., 2016; Xu et al., 2015; Lu et al., 2015; Wang et al., 2018) and ideal technical means for DEM acquisition of wide range, high precision and high time efficiency.

In this paper, TerraSAR-X/TanDEM-X satellite and Bistatic data image pair on January 30, 2013 are used to extract DEM data of Maanshan area. The research obtained good timeliness and high-resolution DEM of Maanshan area based on the iteration and fusion technology using two TerraSAR$\mathrm{X} /$ TanDEM-X SAR images and AW3D30 DEM from JAXA/EORC. And used MATLAB, Surfer to process the experimental DEM and accuracy analysis, finally obtain the accuracy and reliability of the digital elevation model of urban areas.

\section{PRINCIPLE AND METHOD}

InSAR technology used synthetic aperture radar (SAR) to obtain topographic and geomorphic information of the ground area. Through active remote sensing method, the phase difference of two echo signals at different positions in the selected area was obtained to obtain the required information (Burgmann et al., 2000; Rosen et al., 2000; Zhu et al., 2016; Gao, 2017). As shown in figure 1, at different positions of S1 and $\mathrm{S} 2$, SAR sends pulse signals to ground target $\mathrm{P}$ and receives its feedback information. The elevation information $\mathrm{H}$ of ground target $\mathrm{P}$ can be obtained by using geometric parameters as follows: line-of-sight incidence angle $\theta$, radar sensor height $\mathrm{H}$, radar wave length, including Angle between sensor and horizontal direction during the two passes of the radar and baseline length $\mathrm{B}$ during two transit times, and so on.

$$
h=H-R_{1} \cos (\theta)
$$

For the modern urban areas with concentrated high-rise buildings, the elevation difference is larger and the topographic information is more complex. After the image processing with the interference technology, the phase unwrapping of TerraSAR-X/TanDEM-X images at $\mathrm{X}$ band $(3.1 \mathrm{~cm})$ will cause errors due to too dense fringe on the interference pattern. Therefore, the external digital elevation model AW3D30 was

\footnotetext{
* Corresponding author

Ertao Gao - E-mail: gaoertaoswjtu@163.com
} 
used to carry out differential processing of the original interference phase and subtract most of the terrain phase to obtain the residual terrain phase. Then, the residual phase was unwrapped (Zhang et al., 2018) to recover the residual elevation information. Finally, the residual elevation information was superimposed on the original DEM to update the original DEM.

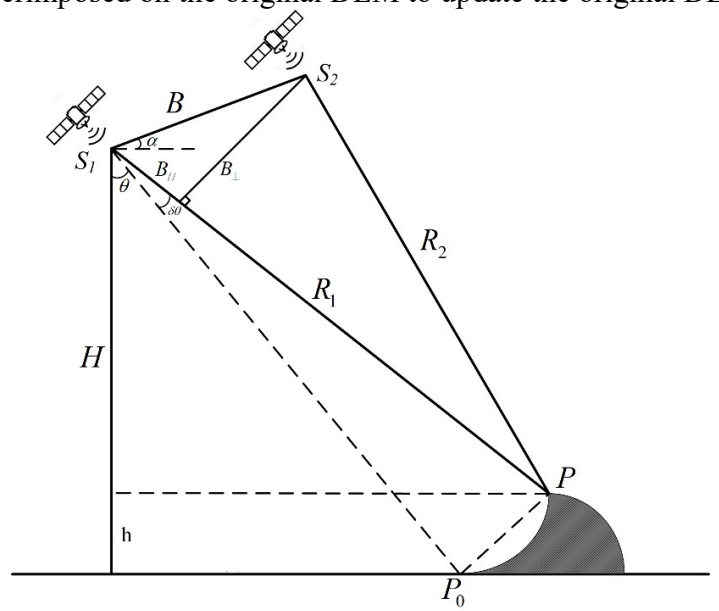

Figure 1 Geometry model calculated by InSAR technology

Due to the difference in resolution between AW3D30 DEM (30 $\mathrm{m}$ ) and TerraSAR-X/TanDEM-X images $(3 \mathrm{~m})$, it is possible to fail to carry out coregistration of the external AW3D30 DEM and the main image of SAR in differential interferometry. Therefore, it should not be set too small in multi-look setting (in principle, the smaller the number of multi-look, the higher the resolution of generated DEM) (Du et al., 2015). In this paper, the experiment of TerraSAR-X/TanDEM-X images for the first of two differential interference, and would be the first to obtain DEM as external DEM of the second differential interference, which have the effect of the iteration, and when setting up more depending on the percentage of the time, the second time depending on the number of much smaller than the first time depending on the number, gradually improving the obtained DEM resolution, thus to obtain high resolution digital elevation model.
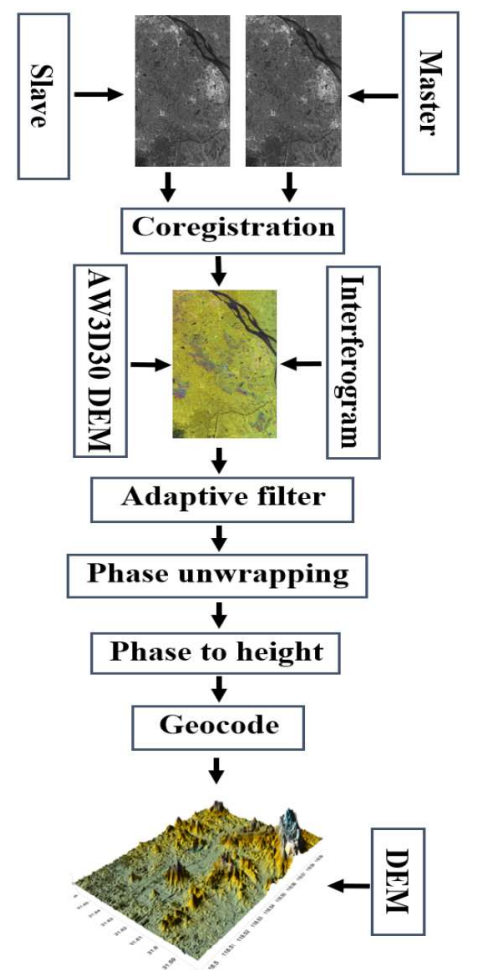

Figure 2 Technological process of extraction of DEM with high resolution

\section{EXPERIMENTAL AND RESULT ANALYSIS}

\subsection{Study area and experimental data}

The research area of this paper was Maanshan area of Anhui province, Maanshan city located in the southeast of Anhui province, bordering Nanjing city of Jiangsu province on the east, Chaohu city on the west, Chuzhou city on the north and Wuhu city on the south. Located at $117^{\circ} 53^{\prime} \sim 118^{\circ} 52^{\prime}$ East longitude and $31^{\circ} 24^{\prime} \sim 32^{\circ} 02^{\prime}$ North latitude, Maanshan covered a total area of 1686 square kilometers. As is shown in figure 3, the main compositions of the downtown are the densely populated high-rise buildings , factories and other features, and other areas are mainly composed of plains and hills, the terrain is high in the east and low in the west, about three-quarters of the elevation in more than $50 \mathrm{~m}$, eastern hilly mountains for 160 $200 \mathrm{~m}$ or so commonly, lakes and river stagger in central plains in which there are also hills. The west, which is along the Yangtze river terrace and flood land with a long and narrow strip of the mound discrete distribution, it's landform information is more complicated.

As shown in figure 3, the red area was the experimental image coverage area. This paper used two ascending SAR images with bistatic data mode, single-polarization $(\mathrm{HH})$, and single look complexly as experimental data from formation flying satellites TerraSAR-X/TanDEM-X. The imaging time was January 30, 2013. The spatial baseline was $248.467 \mathrm{~m}$. The specific parameters were shown in table 1 .

In addition, the AW3D30 data and SRTM data covering in this area were also obtained to compare to analyze the accuracy and reliability of DEM obtained by experiment.

Table1 TerraSAR-X/TanDEM-X image pair parameters

\begin{tabular}{cccccc}
\hline Data & Orbit & Coverage & Resolution & Imaging time & Baseline \\
\hline TDX1_SSC & Ascending & $30 \times 15 \mathrm{~km}$ & $3 \mathrm{~m} \times 3 \mathrm{~m}$ & $2013-01-30$ & $248.467 \mathrm{~m}$ \\
TSX1_SSC & Ascending & $30 \times 15 \mathrm{~km}$ & $3 \mathrm{~m} \times 3 \mathrm{~m}$ & $2013-01-30$ & \\
\hline
\end{tabular}



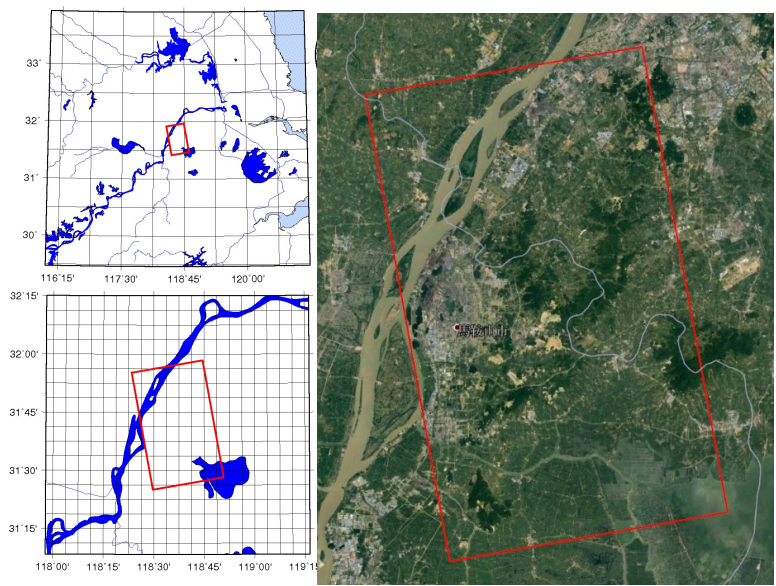

Figure 3 Landform features and footprint of TerraSAR$\mathrm{X} /$ TanDEM-X images around Maanshan area

\subsection{Experimental}

After bistatic data pairs processing, SLC images were obtained (as shown in figure 4), and conjugate multiplication was used to obtain interference phase diagram. The interference pattern was then treated with multiple views to improve the signal-to-noise ratio (Chen et al.,2016). AW3D30 digital elevation model was used for differential processing to deduct most terrain phase information and disperse dense terrain fringe. Due to the higher resolution of the main image TerraSAR-X/TanDEM-X $(3 \mathrm{~m})$ and the lower resolution of the external AW3D30 DEM (30 m), micrognathia multi-look ratio might lead to registration failure in multi-look processing, resulting in the failure of topographic phase deduction. So, the initial interferograms obtained by TerraSAR-X/TanDEM-X had been multi-look processed with the $10 * 10$ range direction and azimuthal direction, consequently, the resolution was about $30 \mathrm{~m}$ after multi-look processing in this paper.
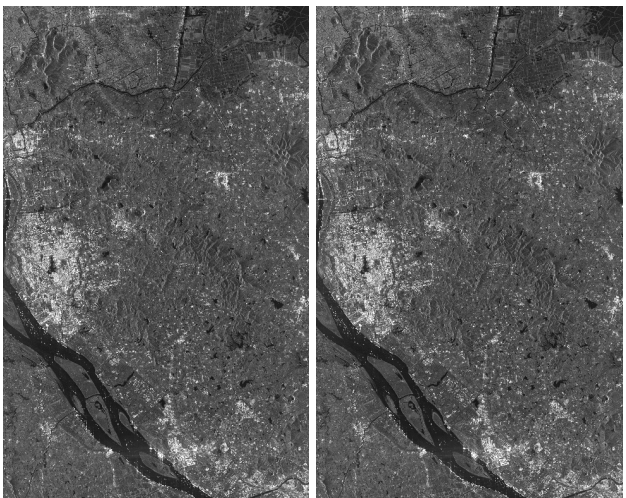

Figure 4 SLC images from this experiment

The differential interferogram was filtered by the adaptive filtering method (Lin et al., 2005), the filtered interferogram and coherence coefficient diagram were obtained. In this paper, MCF method was adopted to unwarp the areas in the filtered differential interferogram whose coherence coefficient was greater than 0.18 . Selecting ground control point was adopted to make correction in the orbit correction (Chen et al., 2014) to optimize the spatial baseline, and the point position with flat terrain and high coherence should be selected in the selection of ground control point. Finally, the residual phase information was converted into elevation information, the residual terrain phase is mainly based on the new terrain features not found in the AW3D30 data (all kinds of large buildings, etc.). The geocoded residual elevation information and the re-sampled AW3D30 data were superimposed to obtain the updated hightime-efficiency digital elevation model.

In order to improve the resolution, this paper adopted the idea of iteration and took the first DEM as the external data reference, and changed it into a multi-view scale. Then, the above experimental process was carried out again to obtain a DEM with higher resolution and better timeliness, finally a digital elevation model with high resolution and good timeliness was obtained. As shown in figure 5 (a), the DEM results of high-precision parts of downtown Maanshan processed by MATLAB and Surfer mapping software were combined. Figure 5 (b) is the relief display mode in Surfer, figure 5 (c) is the Google earth image in the corresponding region.

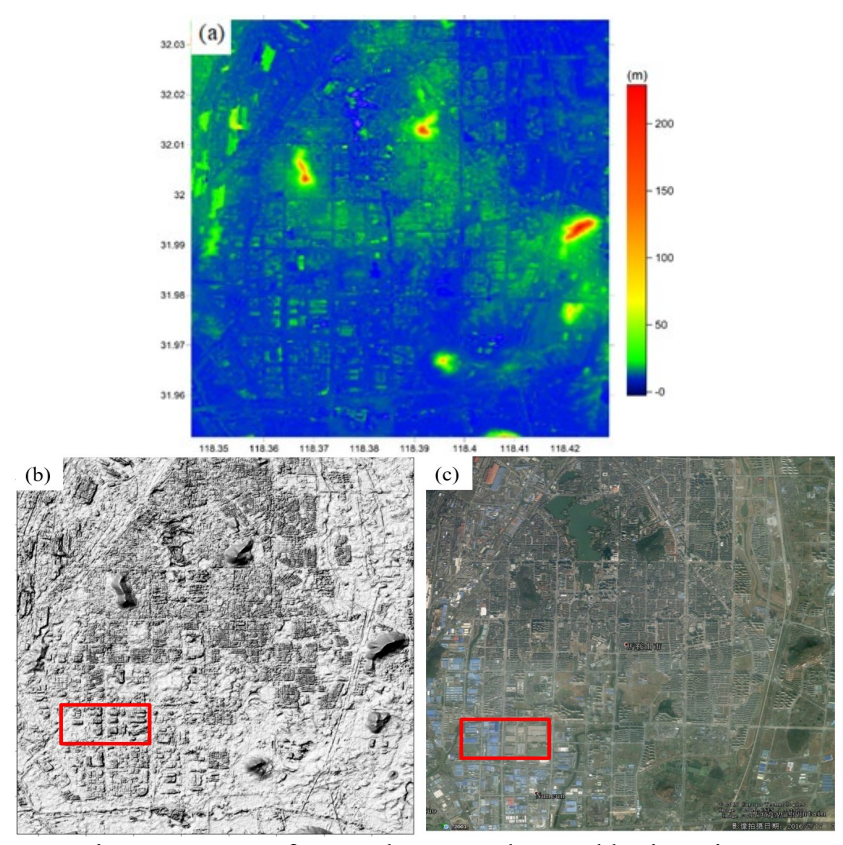

Figure 5 DEM of Maanshan area detected by iteration technology

\subsection{DEM results accuracy analysis}

From figure 5, In this paper, the TerraSAR-X/TanDEM-X image pairs were used to obtain the digital elevation model of the urban area with the iterative idea. The detailed information was well restored in three dimensions, such as mountains, large buildings and other objects with sharp contours. It was well displayed, especially in the area of the red rectangle in the figure 5 (b). The terrain undulation in the picture is within 220 $\mathrm{m}$. Since the city of Maanshan is located on the banks of the Yangtze River, the overall elevation is lower, and most areas are between 10 and 50 meters. 

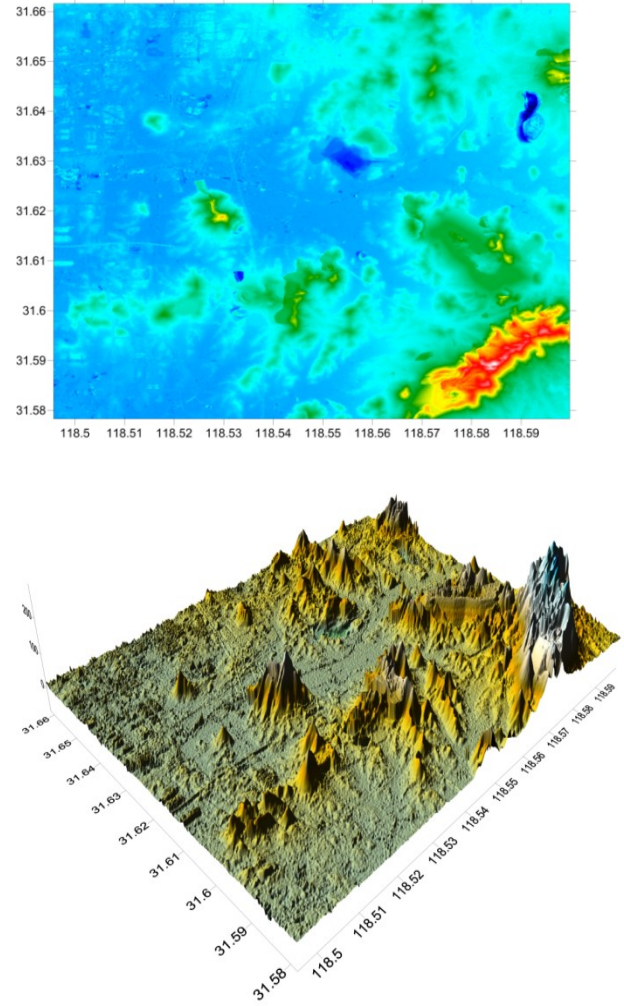

Figure 6 3D expression of DEM in Maanshan

In order to make the $3 \mathrm{~d}$ information of ground objects more intuitive, this paper used MATLAB to cut out the digital elevation model of some areas and displayed it in $3 \mathrm{~d}$. As shown in figure 6 , through the cut DEM and the $3 \mathrm{~d}$ display of the corresponded area, we could clearly see the contour information of the ground features and geomorphology, the densely distributed buildings, the clearly visible hills and so on.
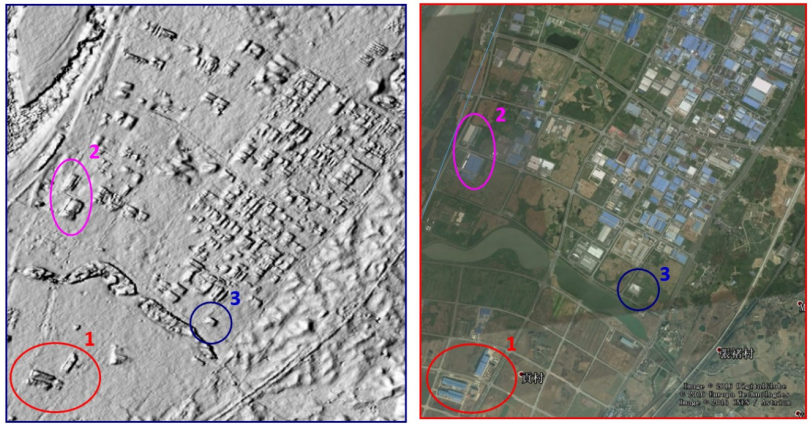

Figure 7 Comparison of DEM model from this experiment with Google image.

As shown in figure 7, this paper compared some areas of downtown Maanshan with Google images. It could be seen from the figure that the DEM obtained in this paper could clearly restore $3 \mathrm{~d}$ detailed information of the research area, especially these single buildings (factories, houses, etc.) which were sparsely distributed. For large-scale distributed linear features (such as high-speed railway), through DEM obtained in this paper, them could still be clearly identified.

In this paper, SRTM and AW3D30 digital elevation models covering Maanshan area were obtained respectively, DEM obtained from the experiment was compared and analyzed to evaluate its accuracy. As shown in figure 8 , in the same area range, from left to right in turn for TerraSAR-X/TanDEM-X access of digital elevation model, AW3D30 data and SRTM data, it can be seen from the diagram that this paper get the DEM could see that the high-speed rail lines was very clear, but unable to reflect the information in other DEM, and resolution was significantly superior to other two international commonly used DEM. Therefore, the digital elevation model obtained by iterative method with high resolution SAR image had better timeliness and resolution.

References should be cited in the text, thus (Smith, 1987a), and listed in alphabetical order in the reference section. The following arrangements should be used:

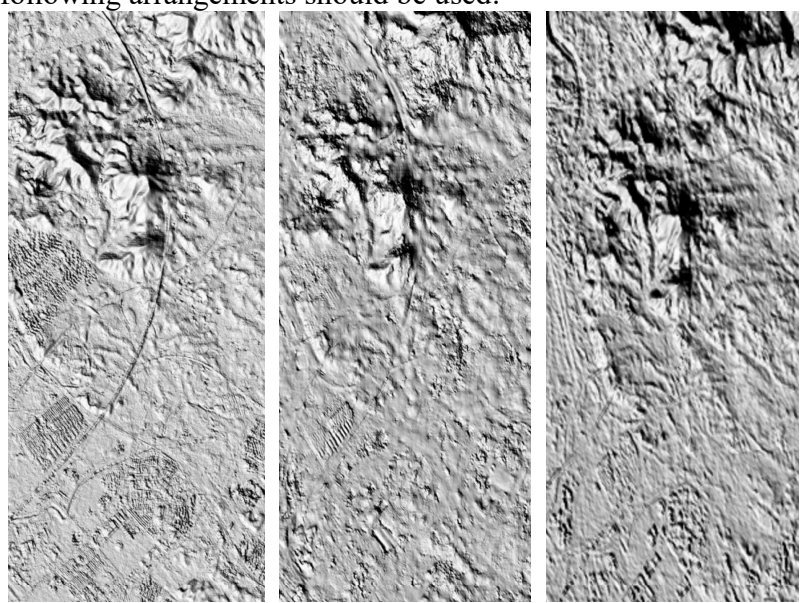

Figure 8 Comparative analysis of DEM model from iteration and fusion technology by TerraSAR-X/TanDEM-X images,

AW3D30 and SRTM

It was found from the figure 8 , in the region of the elevation region (hill), three kinds of DEM elevation recovery effect were higher. But in the area of discrete buildings (structures), comparing with the AW3D30 and SRTM digital elevation models, through the TerraSAR-X/TanDEM-X images to obtain DEM could better restore the three-dimensional information of corresponding object, while SRTM did not show related feature information. For the area of densely distributed buildings or structures, the digital elevation model obtained by the experiment was not considerable enough in this area. One of the main reasons was that the radar sensor would appear overlapping and shadow in the side-view imaging of this area. Especially in the tall buildings with too large difference in height, if the regional phase difference exceeds $2 \pi$, which will interfere with the phase unwrapping and lead to the accuracy reduction of the acquired digital elevation model , even the appearance of voids and other phenomena.

In conclusion, TerraSAR-X/TanDEM-X images pair was adopted to obtain the DEM through iterative thinking, which could better restore $3 \mathrm{~d}$ information of topography and landform and better extract ground details compared with other commonly used DEM in the world. For sparse buildings with strong scattering characteristics, $3 \mathrm{~d}$ information can be well recovered, which provides effective help for the construction of $3 \mathrm{~d}$ models of large buildings in cities. However, due to geometric distortion, perspective contraction and other factors, the precision of the digital elevation model obtained in the densely distributed building area was not ideal.

\section{CONCLUSION}

In this paper, two TerraSAR-X/TanDEM-X satellite bistatic mode images covering Maanshan area were adopted. InSAR 
technique and iterative idea were adopted to improve the resolution of DEM, and the high-resolution and high timeefficient DEM in the research area were successfully extracted. In order to evaluate its accuracy, this paper compared the DEM obtained by TerraSAR-X/TanDEM-X with AW3D30 data and SRTM data, the results shown that for sparse single ground objects, the DEM obtained by this paper had a higher accuracy and could better restore the $3 \mathrm{~d}$ information of ground objects. However, for densely distributed building areas, due to different height of densely distributed buildings, geometric distortion errors and phase unwrapping errors would be occurred in InSAR data processing, which led to the unsatisfactory accuracy of the digital elevation model obtained by the experiment in this area. In the later stage, further research should be conducted on this.

\section{ACKNOWLEDGEMENTS}

This work was supported by National Natural Science Foundation of China (41801071); Guangxi Natural Science Foundation (2017GXNSFDA198016); Guangxi Key Laboratory of Spatial Information and Geomatics Foundation (16-380-2524).

\section{REFERENCES}

Bürgmann, Roland, Rosen P A, et al. 2000. Synthetic aperture radar interferometry to measure earth's surface topography and its deformation[J]. Ann.rev.earth Planet. sci, 28(1): 169-209, DOI: 10.1146/annurev.earth.28.1.169.

Campbell D M H, White B, Arp P A. 2013. Modeling and mapping soil resistance to penetration and rutting using LiDARderived digital elevation data[J]. Journal of Soil and Water Conservation. 68 (6): 460-473, DOI: 10.2489/jswc.68.6.460.

Chen G, Tang X T, Qian F M. 2014. A Three-Dimensional Baseline Calibration Method of Spaceborne InSAR[J]. Geomatics and Information Science of Wuhan University, 39(1): $37-41$

Chen J H, Zhao Y J, Lai T, et al. 2016. Fast Non-local Means Filtering of SLC Fully PolSAR Image[J]. Geomatics and Information Science of Wuhan University, 41(5): 629-634.

Du Y N, Feng G C, Li Z W et al. 2015. Generation of high precision DEM from TerraSAR-X/TanDEM-X[J]. Chinese Journal of Geophysics, (09): 3089-3102.

Gao E T, Fan D L, Fu B L et al. 2019. Land subsidence monitoring of Nanjing area based on the PSInSAR and SBAS Technology[J]. Journal of Geodesy and Geodynamics, 39(02):158-163, DOI: 10.14075/j.jgg.2019.02.010.

Gesch D B, Oimoen M J, Zhang Z et al. 2012. Validation of the ASTER Global Digital Elevation Model Version 2 over the conterminous United States[J]. ISPRS - International Archives of the Photogrammetry, Remote Sensing and Spatial Information Sciences, XLI-B4: 143-148, DOI: 10.5194/isprsarchives-XXXIX-B4-281-2012.

Guo L P, Yue J J, Yue S. 2017. Application of SBAS Technique in Surface Subsidence Monitoring of Nanjing Hexi Area[J]. Bulletin of Surveying and Mapping, (03):26-28+41.
Huang G, Liu L R, Shi X J et al. 2017. Accuracy analysis of DEM based on domestic airborne mini-InSAR system[J]. Science of Surveying and Mapping. 42(8): 124-129.

Jain A O, Thaker T, Chaurasia A et al. 2017. Vertical accuracy evaluation of SRTM-GL1, GDEM-V2, AW3D30 and CartoDEM-V3.1 of 30-m resolution with dual frequency GNSS for lower Tapi Basin India[J]. Geocarto International, 1-20, DOI: $10.1080 / 17538947.2018 .1458163$.

James M R, Robson S. 2012. Straightforward reconstruction of 3D surfaces and topography with a camera: Accuracy and geoscience application[J]. Journal of Geophysical Research, v. 117: F03017, DOI: 10.1029/2011JF002289.

Li P C, Wang H, Liu Z Q et al. 2012. A Method of Deriving DEM from Airborne LiDAR Points Cloud Date[J]. Unmanned Aircraft. Bulletin of Surveying and Mapping, (05): 59-62.

Li T, Tang X M, Gao X M, et al. 2017. Spaceborne InSAR Topographic Surveying and Mapping Error Sources Analysis[J] Bulletin of Surveying and Mapping, (11):37-41+50

Lin H, Zhao C S, Du P J, et al. 2005. Research on Filtering Methods of InSAR Interferogram[J]. Acta Geodaetica et Cartographica Sinica. 34(2): 113-117.

Lu Q Y, Zheng Q, Sun J B, et al. 2015. Coseismic deformation field of 2015 Nepal earthquake (MW 7.8) detected by new generation satellite radar interferometry data[J]. Progress in Geophysics (in Chinese), 30(6): 2505-2510.

Nikolakopoulos K G, Kamaratakis E K, Chrysoulakis N. 2006. SRTM vs ASTER elevation products. Comparison for two regions in crete, Greece $[\mathrm{J}]$. International Journal of Remote Sensing, 27(21): 4819-4838, DOI: $10.1080 / 01431160600835853$.

Qiu C X, Dong Q K, Liu R H, et al. 2017. Refining Model of 3D Modeling Based on Oblique Image of Unmanned Aircraft[J]. Bulletin of Surveying and Mapping, (11): 133-138+143.

Pitz W, Miller D. 2010. The TerraSAR-X Satellite[J]. IEEE Transactions on Geoscience and Remote Sensing, 48(2): 615622, DOI: $10.1109 /$ tgrs.2009.2037432.

Rabus B, Eineder M, Roth A. 2003. The Shuttle Radar Topography Mission (SRTM) - A New Class of Digital Elevation Models Acquired by Spaceborne Radar[J]. ISPRS Journal of Photogrammetry and Remote Sensing, 57(4): 241262, DOI: 10.1016/S0924-2716(02)00124-7.

Rawat K S, Mishra A K, Sehgal V K. 2013. Comparative evaluation of horizontal accuracy of elevations of selected ground control points from ASTER and SRTM DEM with respect to CARTOSAT-1 DEM: a case study of Shahjahanpur district, Uttar Pradesh, India[J]. Geocarto International, 28(5): 439-452, DOI: 10.1080/10106049.2012.724453.

Rosen P A, Hensley S, Joughin I R, et al. 2000. Synthetic aperture radar interferometry[J]. Proceedings of the IEEE, 88(3): 333-382, DOI: 10.2528/pier11042301.

Solberg S, Riegler G, Nonin P. 2014. Estimating Forest Biomass From TerraSAR-X Stripmap Radargrammetry[J]. 
IEEE Transactions on Geoscience \& Remote Sensing, 53(1): 154-161, DOI: 10.1109/TGRS.2014.2319853.

Sun W, Zhu C, Wang X C, et al. 2011. Investigation of Geothermal Resource and Geologic Hazards at Mufu Mountain Area in Nanjing[J]. Journal of Mountain Science, 29(6): 753758.

Wang Y X, Zhao C Y, Yin H F. 2018. Review: deformation time series method with InSAR techniques[J]. Progress in Geophysics (in Chinese), 33(4): 1430-1437.

$\mathrm{Xu} \mathrm{C}$ J, He P, Wen Y M, et al. 2015. Recent Advances InSAR Interferometry and Its Applications[J]. Journal of Geomatics, 40(2):1-9.

Xu C J, Wang H. 2004. Comparison of InSAR Phase Unwrapping Algorithms and Error Analysis[J]. Geomatics and Information Science of Wuhan University, 29(1): 67-71.

Zeng Q M, Zhang X J, Jiao J. 2016. Atmospheric correction of spaceborne repeat-pass InSAR DEM generation based on WRF[J]. Journal of Remote Sensing. 20(05): 1151-1160.

Zhang X L, Zhang X C, Zhang H, et al. 2018. Phase unwrapping in digital holography based on non-subsampled contourlet transform[J]. Optics Communications. 407: 367-374, DOI: $10.1016 /$ j.optcom.2017.09.057.

Zhao Z. 2016. Methods on High-accuracy DEM Extraction from Interferometric SAR in Sophisticated Terrain Areas[J]. Acta Geodaetica et Cartographica Sinica. 45(11): 1385-1385.

Zhu J J, Li Z Z, Hu J. 2017. Research Progress and Methods of InSAR for Deformation Monitoring[J]. Acta Geodaetica et Cartographica Sinica, 46(10): 1717-1733.

Zhu S, Xu C J, Wen Y M, et al. 2016. Interseismic Deformation of the Altyn Tagh Fault Determined by Interferometric Synthetic Aperture Radar (InSAR) Measurements[J]. Remote Sensing, 8(3): 233-, DOI: 10.3390/rs8030233. 